IRA-International Journal of Management \& Social Sciences

ISSN 2455-2267; Vol.15, Issue 02 (May, 2019)

Pg. no. 16-26.

Institute of Research Advances

http://research-advances.org/index.php/RAJMSS

\title{
Determinants of Household Conspicuous Consumption on Wedding Ceremony in Adi- Keih, Eritrea
}

\author{
Ghirmai Tesfamariam Teame ${ }^{1 \#}$, Berhane Mehari Andom², Filimon Haile Tekleab ${ }^{3}$, \\ Yafiet Dawit Araya ${ }^{4}$ \& Yonas Nuguse Ghebreab ${ }^{5}$ \\ ${ }^{1}$ Assistant Professor, Department of Economics, College of Business and Social Sciences, Adi- \\ Keih, Eritrea. \\ ${ }_{2,3,4,5}$ College of Business and Social Sciences, Adi-Keih, Eritrea. \\ \# corresponding author \\ Type of Work: Peer Reviewed. \\ DOl: http://dx.doi.org/10.21013/jmss.v15.n2.p1 \\ How to cite this paper: \\ Teame, G.T., Andom, B.M., Tekleab, F. H., Araya, Y. D., Ghebreab, Y. N. (2019). \\ Determinants of Household Conspicuous Consumption on Wedding Ceremony in Adi- \\ Keih, Eritrea. IRA-International Journal of Management \& Social Sciences (ISSN 2455-2267), \\ 15(2), 16-26. doi:http://dx.doi.org/10.21013/jmss.v15.n2.p1
}

(C) Institute of Research Advances.

(cc) EY-NC

This work is licensed under a Creative Commons Attribution-Non Commercial 4.0 International License subject to a proper citation to the publication source of the work.

Disclaimer: The scholarly papers as reviewed and published by the Institute of Research Advances (IRA) are the views and opinions of their respective authors and are not the views or opinions of the IRA. The IRA disclaims of any harm or loss caused due to the published content to any party.

Institute of Research Advances is an institutional publisher member of Publishers International Linking Association Inc. (PILA-CrossRef), USA. The institute is an institutional signatory to the Budapest Open Access Initiative, Hungary advocating the open access of scientific and scholarly knowledge. The Institute is a registered content provider under Open Access Initiative Protocol for Metadata Harvesting (OAI-PMH).

The journal is indexed \& included in WorldCat Discovery Service (USA), CrossRef Metadata Search (USA), WorldCat (USA), OCLC (USA), Open J-Gate (India), EZB (Germany) Scilit (Switzerland), Airiti (China), Bielefeld Academic Search Engine (BASE) of Bielefeld University, Germany, PKP Index of Simon Fraser University, Canada. 


\begin{abstract}
The level of household consumption expenditure indicates and is critical for enhancing the level of economic development as well as the wellbeing and wealth of societies. Conspicuous consumption, one component of the household consumption expenditure, includes the practice of purchasing goods or services for public display of wealth or status-seeking rather than covering basic needs and is common practice in developed and developing economies. One form of conspicuous consumption, households engaged in, is the extravagant spending on wedding celebrations, which have grown prohibitively expensive over time. The study, based on an OLS model, tries to investigate the determinants of household conspicuous consumption on a wedding ceremony in Adi-Keih town, Eritrea. The result of the study, based on household survey data, shows that on the average, households spend more than twice of their annual income on the wedding ceremony. Moreover, it reports that age, religion and level of education of the head of household, the total yearly income of the household, and financial support from abroad have significant effects on the level of conspicuous consumption on wedding ceremony. Based on these, policies on how to minimize the disproportionately large amount of spending that is diverted to signalling status are recommended.
\end{abstract}

Keywords: Conspicuous consumption, wedding ceremony, OLS regression, Eritrea.

\title{
1. Background
}

The level of household consumption expenditure makes up the most significant component of an economy's GDP and thus indicates the level of economic growth of society as a whole. Therefore, consideration of household consumption expenditure is closely interrelated and is critical for enhancing the level of economic development as well as the wellbeing and wealth of societies. According to [51], the level of household consumption expenditure is a measure of material wellbeing for the community in which their economy is highly dependent on subsistence agriculture and remittance. Consequently, this raises the question of the types of consumption expenditure households engaged in and what are the factors that influence the magnitude of these expenditures in a given society.

One component of the household consumption expenditure, which includes the practice of purchasing goods or services for public display of wealth or commonly known as status-seeking consumption rather than covering basic needs, is called conspicuous consumption and is common practice in developed and developing economies. Ref.[9], for example, has emphasized that households in less developed countries are often engaged in status-seeking consumption even before covering their basic needs for shelter and food. Consequently, it results in suffering and loss of good opportunities or loss of resources that contain high development potential had the money been used on more productive consumption expenditures.

Spending money to advertise one's success is not a new phenomenon; rather it dates back to tribal times when men possessed women and slaves as trophies of their status [49]. Since that time, although the players and what is consumed have changed, the game of ostentatious consumption has remained mostly the same, with the winners being awarded status, prestige and honour [39]. The desire to conspicuously consume is timeless and not limited to only a particular class in society: all kind of income groups, races [16, 30] and members of political regimes [22] appear to be involved in these ostentatious practices. However, the term is often used in a vague descriptive sense to refer to any non-utilitarian forms of consumption, or directly to that which is judged extravagant, luxurious, or wasteful $[13,33]$.

One form of conspicuous consumption, households engaged in, is the extravagant spending on wedding celebrations. In many settings, these expenses have grown prohibitively expensive, with costs totalling several times the total annual household income. This cost escalation may be attributed to rising aspirations, to signal social status or due to increasing standards of living. It is a well-known fact that wedding traditions and customs and their financial aspects vary significantly between cultures, ethnic groups, religions, countries, and social classes and have changed over time. In many cultures, a large proportion of wedding costs are in the form of dowries-transfers, and the rest is spent in celebrating the wedding, and the size of the celebration is usually justified as being forced by norms in the community that are traditionally determined by observing the scale of other recent weddings in the community. Besides, many families tend to have particularly excessive wedding celebrations influenced less by norms in the communities and more by the ambition to show off their economic 
power or status. The phenomenon becomes even severe since low-income families are dragged, either willingly or not, to imitate the more extravagant patterns common in more prosperous families. Therefore, it is argued that, although competition in its good nature is an incentive for better economic performance, competition in the opposite scheme for showing economic power or status through tremendous spending on wedding and other cultural ceremonies have detrimental effects on the livelihood of households in almost all developing societies. Because it crowds out investments on human capital, jeopardizes future consumption, and obstructs the whole development process.

Historically, in many parts of Eritrea, all weddings were celebrated modestly. Couples got married during Sunday mass and then went to the house of the groom's family. A cow or an ox is slaughtered on the wedding day. For entertainment, the wedding party sang traditional songs. The, rather simple, wedding script differs substantially from the lavishness and complexity of today's weddings in rural and urban Eritrea. It has become costly as well as the most critical arena for expressing class distinction by blending local ritual practices with Western middle-class consumption habits. Thus, current wedding celebrations in Eritrea have gradually developed into costly celebrations. However, such celebrations are, of course, not unique to Eritrea, but are of particular relevance in many developing societies. Given its high opportunity cost, the money spent on such wedding celebrations can be considered wasteful. Nevertheless, from the individual's point of view, this sort of consumption is, of course, not wasteful; and the utility, which is gained, results not from the act of consumption itself, rather from the status, which is bestowed on the consumer, through the eyes of observers.

The study intends to investigate the determinants of household conspicuous consumption expenditure on wedding ceremony in Adi-Keih town, Eritrea. It aims to examine how households with different characteristics and demographics could show a difference in their conspicuous consumption habits on wedding ceremonies. Thus, the remainder of the paper is organized as follows. Section two provides a statement of the problem, objectives of the study and the research questions the study tries to address. Section three presents a review of some of the available literature. The research methodology is given in section four. Empirical results of the study and conclusion and recommendations are provided in section five and six, respectively.

\section{Statement of the problem and objectives of the study}

Many types of research have argued that conspicuous consumption expenditures are merely a miss utilization of resources with a zero-sum game to the wellbeing of the consumer, as it crowds out investments, such as healthcare, food or education by a household. Shreds of evidence also show that conspicuous consumption may even influence the likelihood of poverty traps [34], especially since the poorest have more incentives to spend a larger proportion of their income on status consumption and invest less on human capital. Moreover, future consumption and savings are likely to be jeopardized [16]. Consequently, conspicuous consumption slows down or even obstructs the whole development process. Despite these facts, most of the empirical research on the reasons, nature, determinants, effects and other aspects of conspicuous consumption has been carried out in the developed countries. However, studies show that even households in developing countries are engaged in statusseeking consumptions by spending a substantial amount on entertainment, clothing and festivals, even before food and shelter are entirely covered. As argued by [14, 9, 12, 31, 38, 48], households in developing countries may have relatively higher levels of conspicuous consumption, because of extreme inequalities in income, relatively stronger social relationships and traditions and the urge to show off of the nouveaux riches [33]. Thus, even though, conspicuous consumption on wedding seems to have significant implications for the livelihood of households in developing countries in general and Eritrea in particular, to the best of our knowledge, no empirical studies have been conducted on the determinants of this behaviour in Eritrea. The primary purpose of this study is, therefore, to fill the gap in the available literature by shedding light on the determinants of household conspicuous consumption on wedding ceremony in Adi-Keih town, Eritrea; and to draw some policy implications to tackle its negative impacts on the livelihood of households.

Therefore, the main objectives of the study can be summarized as follows:

1. To quantify and shed light on the extent of household conspicuous consumption expenditure on wedding ceremony; and 
2. To identify the factors that determine the level of household conspicuous consumption expenditure on wedding ceremony in Adi-Keih town, Eritrea.

These may help to understand better the nature of the factors that determine the level of status-seeking spending on wedding ceremonies in Eritrea. Moreover, the results of the study will have policy implications in the debate on how to minimize the disproportionately more substantial amount of consumer spending that is diverted to signalling status and in identifying priorities, and it can also be used as a base for further research.

The study, which addresses the above-stated objectives, is designed to answer the following research questions:

1. What is the level of household conspicuous consumption expenditure on wedding ceremony?

2. Is there a relationship between the level of total household income, household size, head of household level of education, religion, employment statuses and other factors at household or head of household level and the level of conspicuous consumption expenditure on wedding ceremony?

3. What can be done to reduce the level of status-seeking consumption spending on wedding ceremonies?

\section{Literature Review}

The neoclassical utilitarian consumption function states that consumers are rational, and act in a way that maximizes their utility with a constrained financial resource or minimize their cost with a given level of utility. According to [23], the basic neoclassical theory of consumption largely disregards the effect of interpersonal effects on individual consumption decisions. However, making several insightful observations regarding human beings, their social interactions and their consumption decisions, [49], in his book The Theory of the Leisure Class, has provided a powerful critique of the neoclassical consumption theory [47]. In contrast to the neoclassical approach, which assumes the individual's maximization of utility according to exogenous preference, Veblen developed an evolutionary framework in which preferences are determined socially and psychologically in relation to the positions of individuals in the social hierarchy [50]. These social and psychological motives of consumption are especially evident when it comes to luxury goods that seek to imply status to the consumer. Some of these motives are focused on the experience and appreciation of the individual. For example, quality assurance can be a motive for a consumer to prefer expensive goods above cheaper ones, assuming that expensive products have a superior condition; or status goods are consumed because of their hedonic aspect. Alternately, [32] has emphasized that the social aspect is another important motive for status consumption and can be divided into three sub motives. These are: as a means for acquiring a unique identity, for social conformity, where individuals attempt to adhere to the norms and standards of their social group that also affects their purchasing behaviour, and in the hope to be perceived more favourably in the higher social hierarchy $[35,50]$.

Due to the composite nature of the phenomenon, which requires multidisciplinary analysis combining viewpoints from economics, marketing, sociology, psychology and even biology it is almost impossible to give an exhaustive definition of the concept. However, reformulating the arguments given by Veblen, conspicuous consumption can be defined as the consumption of goods and services that are motivated mainly by the secondary (conspicuous) utility, which is derived from social confirmation of the consumer's relative ability to pay [7]. Broadly, it is a tendency to show an individual's wealth, status and prestige to others through consumption [44], commonly focusing on a visual display of products in front of other individuals or groups of people [36]. Consumers make their decisions to buy and consume conspicuous goods, paying attention not only to the material needs that these products can satisfy but also to social needs such as honour, prestige, and esteem within the community and their psychological satisfaction related to admiration and experience of an individual for the product $[2,9,26,50]$. Hence, individuals, not only the rich but also members of the middle and working class, are involved in a competitive race for gaining status or prestige [33].

Ref. [42] is one of the first to draw attention to the phenomenon of conspicuous consumption. He acknowledged that the utility people derive from luxury goods stems almost entirely from their high price, rather than from their intrinsic qualities. However, Veblen is the first theorists to argue that consumption is a process of socialization and goods have a function as markers of social class [40]. Similarly, [19] has contributed one of the early literature on the topic and argued that a person's conspicuous consumption depends not only upon the 
actual level of spending but also upon the degree of his or her spending, as compared with and to the spending of other people. Thus, despite the fact that modern literature on conspicuous consumption behaviour is sparse, the interest in it was revived by [8,21,22]. Their works have been extended by [28, 5] who develop models of conspicuous consumption as a signal of wealth. Moreover, [18] have further extended this to allow for bandwagon and snob effects, and [24] has applied the idea to explain charity [11]. Some researchers have also focused on the effect of a single variable on conspicuous consumption. For example, [37] have examined the effect of income inequality, [27] has focused on the effect of income and Childermas, and Rao (1992) have solely studied the influence of peer-based reference groups on conspicuous consumption decisions. Similarly, $[16,30]$ have examined the differences in status-seeking spending between race groups in contemporary South Africa and in the USA, respectively. The results of their studies have reported that non-White households spend relatively more (30 to 50 per cent more) on visible consumption than do comparable White ones in South Africa, and Blacks and Hispanics spend larger shares of their total expenditure on conspicuous goods than do comparable Whites in the USA [33].

Income can be treated as a resource as well as a position in society. Thus, [40] has argued that wealthy individuals often consume highly conspicuous goods and services in order to advertise their wealth, thereby achieving higher social status. On the other hand, [30, 34] have reported that the poor spend more on status consumption and invest less in human capital, as an answer to their feelings of relative deprivation. Moreover, [29] have shown that conspicuous goods can serve as a substitute for educational qualifications and professional titles. It gives the highly educated ones, those who have an observable ability displayed by professional titles, degrees certificates and diplomas, to have relatively little need to signal success, while those without education and thus without certified accomplishment to have stronger motive to impress others by spending on conspicuous goods and services [50] On the contrary, [1,15, 52] have reported that higher levels of education generally bring higher access to financial resources and a stronger need to signal the achieved wealth, status and prestige [33]. Furthermore, according to [25, 45], because of their great attention to others and mass media, young individuals are the conspicuous consumers par excellence. Moreover, middle-aged individuals have generally relatively higher incomes, a more stable career and higher access to credit and debit resources, which give them higher capacities to pay for conspicuous consumption [33, 46]. However, due to the difference in social, economic, political, historical or legal backgrounds, it should be mentioned that the impact of the aforementioned factors on conspicuous consumption patterns may vary from one society to another.

When we come the nature of conspicuous consumption spending on wedding ceremonies, [10] have pointed out that weddings in India have a conspicuous nature; where the poor households spend relatively much on weddings and dowries to signal status [3]. They demonstrate based on survey data from South India that a daughter's marriage (dowry plus celebrations) is the costliest event in the life of an Indian family and can amount to more than six times a family's annual income. It often drives parents into severe debt at high interest rates and may push families into deep poverty [50]. Similarly, [43] has reported that families that can barely scrape out an existence spend on average no less than 15 per cent of their total expenditure on festivals and spend up to 6 times their annual income on a daughter's wedding ceremony (excluding dowry). Belonging to the rare collections on the pattern of conspicuous consumption spending on wedding ceremonies in Sub Saharan Africa, [41] has stated that weddings have become the most critical arena for expressing class distinction in Fransfontein, Namibia. Similarly, [4] provides some evidence from Niger, where a poor rural family typically spends an amount over the country's annual per capita income on prestige goods for wedding ceremonies.

\section{Research methodology}

The area selected for the study is Adi-Keih town, which is one of the administrative sub-Zobas (sub-regions) of Zoba Debub (Southern Region), Eritrea. The choice of the study area was purposive, taking time and financial constraints into account and its proximity to the College of Business and Social Sciences, Adi-Keih. ${ }^{1}$ Primary data were collected at a household level, following stratified sampling technique based on zonal locations (administrative regions) of the households. For this purpose, a standardized questionnaire was developed and

\footnotetext{
${ }^{1}$ The data is part of a senior thesis of the students of the Department of Economics, College of Business and Social Sciences, Adi-Keih.
} 
administered to 102 households who had wedding ceremonies between May 2017 and May 2018. The data were collected through formal interviews with household heads, which are selected from four administrative regions of the study area, following the snowball-sampling technique. Snowball sampling is a non-probability sampling technique, where existing study subjects recruit future subjects from among their acquaintances. Thus, the sample group appears to grow like a rolling snowball. Snowball sampling is often used because the population under investigation is hard to be approached, either due to low numbers of potential participants or the sensitivity of the topic. One advantage of snowball sampling is, it is possible for the surveyors to include people in the survey that they would not have known.

When we take the intricate nature of the issue into account, it is practically impossible to give a thorough list of motives and factors that could be considered as the determinants of households conspicuous consumption patterns on wedding ceremonies. Hence, only some of these influencing factors such as total household income, household size, and other characteristics of a household are considered. Moreover, the household head is assumed to be the leading decision maker and the one who is responsible for the allocation of household resources. Thus, traits of household head, like sex, age, employment status and level of education and religion, which are most likely to affect the involvement of the household in conspicuous consumption, are considered. The list of the dependent and independent variables and how they are measured are described below.

In our study, the level of household conspicuous consumption expenditure on a wedding ceremony is considered as a dependent variable and it is denoted as cons. It is measured as a sum of expenditures related to the wedding ceremony on sustenance, dowry or festoon, transport, band and video expenditures, gold, cloth and other expenses by a household. Description of the independent variables that are related to the household head characteristics is given below. The religion of the head of the household shows whether the household head is Christian or Muslim, and it is expressed as a categorical or dummy variable, which takes the value of 1 for Christian and 0 for Muslim, and it is denoted as Relg. Moreover, the employment status is measured as a categorical variable taking the value of 1 for an employed household head (either wage or self-employed) or 0 for the head of a household who is unemployed or not in the labour force. Sex of head of household, which is denoted as Sex_HOH, takes the value of 1 for male-headed household and 0 for female-headed household, is also included.

The variable household size, denoted as $H_{H}$ size, refers to the number of members in the household who usually eat from the same pot and sleep under the same roof. It also includes members of the household who are absent for less than two months. Similarly, the yearly income of a household, represented as Yrly_Inco, is measured as a sum of the annual income of all household members. It includes income earned from farm and non-farm or off-farm activities (be it from wage or self-employment), annual remittance received by a household, and another source of income such as a pension, government transfer payments, transfer from members of the household who are in national service, and rent. In addition to these variables, financial support from abroad for the lane of marriage, which is measured as a dummy variable taking the value of 1 if the household receives any financial support for wedding celebration and 0 otherwise, is considered and is denoted as Fin_Abroad.

\section{Results of the study}

First, we present descriptive statistics of the variables to examine the nature of the data. As shown in table 1 , the average expenditure on wedding ceremony per household is about Nakfa 81,898. It is a tremendous amount of spending, which crowds out investment and other opportunities, compared to a household average yearly income of Nakfa 39,549. The result of the study shows that, on average, households spend around 207 per cent of their annual income on wedding ceremonies. Moreover, the minimum and maximum age of household heads in our sample is 22 and 78 years, respectively; and the majority of them are between 45 and 60 years, with a mean age of 54.02 years and standard deviation of 10.51 years. On the average, the level of education of the household heads is 6.44 completed years of schooling, with a standard deviation of 4.538 completed years of schooling, and the highest level of education which is attained by the head of the household is first degree. Among the sampled households, the maximum and a minimum number of household size is nine and two, respectively. When we see into the data more closely, 68.5 per cent of the households have less than or equal to five members and the rest of the households have greater than five members. Finally, the mean household size is 
4.91 members with a standard deviation of 1.866. The data also shows that 42.6 per cent of the sampled households are female-headed, while 57.4 per cent of them are male-headed. In addition to these, 85.2 per cent of the sampled households are Christians, and the remaining 14.8 per cent are Muslims. Moreover, 33.3 per cent of the head of the sampled households is unemployed while 66.7 per cent of them are employed.

Table 1: Descriptive Statistics

\begin{tabular}{|c|c|c|}
\hline Variable & Mean & Std. Deviation \\
\hline Cons_con & 81898.93 & 26590.31 \\
\hline Yrly_inco & 39549 & 16010.37 \\
\hline Age_HOH & 54.02 & 10.514 \\
\hline HH_Size & 4.91 & 1.866 \\
\hline Edn_HOH & 6.44 & 4.538 \\
\hline
\end{tabular}

Moreover, to empirically examine the relationship between the above mentioned dependent and independent variables, we have constructed a multiple regression model based on an OLS method and then tested which factors have a significant effect on household conspicuous consumption spending on wedding ceremony. The functional form of the model, upon which the study is based, is presented below. Note that the level-level form (linear specification) has been used. The term UI (error term), reflects the effect of all other (unobserved) factors; factors other than the independent variables which are not included in our model but may have any influence on the dependent variable.

$$
\begin{aligned}
& \text { Con_Con }=\beta_{0}+\beta_{1} \mathrm{Age}_{-} \mathrm{HoH}+\beta_{2} \mathrm{Sex} \_\mathrm{HoH}+\beta_{3} \mathrm{Edn} n_{-} \mathrm{HoH}+\beta_{4} \mathrm{HH} H_{-} \text {Size }+\beta_{5} \text { Relg } \\
& +\beta_{6} \mathrm{Yrly}_{-} \text {Inco }+\beta_{7} \mathrm{Empl} \mathrm{H}_{-} \mathrm{HoH}+\beta_{8} \text { Fin_Abroad }+U_{i}
\end{aligned}
$$

Table 2: Regression Output

Dependent Variable: Con_Con

Method: Least Squares

Sample: 1102

Included observations: 102

\begin{tabular}{crccc}
\hline \hline Variable & Coefficient & Std. Error & t-Statistic & Prob. \\
\hline \hline C & 73742.16 & 30274.12 & 2.435815 & 0.0189 \\
Age_HoH & -1020.593 & 480.7595 & $-2.122875^{*}$ & 0.0393 \\
Sex_HOH & -356.3688 & 11688.01 & -0.030490 & 0.9758 \\
Edn_HoH & -1155.519 & 170.807 & $-6.765056^{* *}$ & 0.0000 \\
HH_Size & 1890.794 & 2530.980 & 0.747060 & 0.4589 \\
Relg & 28563.10 & 12729.63 & $2.243828^{*}$ & 0.0298 \\
Yrly_Inco & 0.394023 & 0.054484 & $7.231849^{* *}$ & 0.0000 \\
Empl_HoH & 9479.412 & 12607.58 & 0.751882 & 0.4560 \\
Fin_Abroad & 0.505769 & 0.105824 & $4.779346^{* *}$ & 0.0000 \\
\hline \hline R-squared & 0.722835 & Mean dependent var & & 100948.6 \\
Adjusted R-squared & 0.673561 & S.D. dependent var & & 55267.34 \\
S.E. of regression & 31576.90 & Akaike info criterion & & 23.70925 \\
Sum squared resid & $4.49 E+10$ & Schwarz criterion & & 24.04075 \\
Log-likelihood & -631.1498 & Hannan-Quinn criter. & & 23.83710 \\
F-statistic & 14.66977 & Durbin-Watson stat & & 2.230883 \\
Prob(F-statistic) & 0.000000 & & \\
\hline \hline
\end{tabular}

**, * indicates statistical significance at $1 \%$ and $5 \%$ level of significance 
The result of our regression output shows that the age of household head has a negative and statistically significant effect (at a 5 per cent level of significance) on conspicuous spending on wedding ceremony. Our result implies that ceteris paribus when the age of household head increases by one year, the level of conspicuous consumption on wedding ceremony decreases by Nakfa 1,104.20. Based on the relevant literature, the expected sign of the age of head of household on the level of conspicuous consumption spending on a wedding ceremony is negative; implying that as head of the household gets older, the level of conspicuous consumption on wedding ceremony decreases. It might be because conspicuous consumption is aimed at the process of gaining social status and it could be assumed that younger household heads are at the start of this status-seeking process. This group, therefore, should do more to validate oneself and build up a reputation. Furthermore, younger and middle-aged household heads are more likely to have relatively higher income, a more stable career and higher access to credit and debt resources, which give them higher capacities to pay for conspicuous consumption $[33,46]$. Hence, households headed by younger people are more likely to consume conspicuously. On the other hand, the elderly have already acquired a certain level of status throughout the years; thus, they are likely to spend less on status-seeking consumption.

A higher level of education is generally associated with an observable ability, displayed by professional titles, degrees, certificates and diplomas; thus, less need to signal status or prestige through conspicuous consumption. It is believed that conspicuous goods can serve as a substitute for educational qualifications and professional titles. The results of our study, therefore, confirms the above-stated hypothesis by reporting a negative and statistically significant relationship between the level of education of the head of the household and level of conspicuous spending on the wedding ceremony, at 1 per cent level of significance. Therefore, the result of our study reported a relatively higher level of conspicuous consumption accompanying a lower level of education of the head of household, as it derives a stronger motive to impress others by engaging in conspicuous consumption.

Similar to other social institutions, religion influences the economic activities of a household. Since religion generally guides a household or a society what to do and not to do, it affects the culture of work, consumption, and even expenditure on marriage and other social ceremonies. Therefore, there is a difference in the level of spending on a wedding ceremony based on the household religion. The result of our study reports that religion has a positive and statistically significant effect on the level of conspicuous spending on the wedding ceremony, at a 5 per cent level of significance. Since religion, in our case, is represented by a dummy variable, we can conclude that keeping the effect of other variables constant, the level of conspicuous consumption on wedding ceremony by a Christian household is higher by Nakfa 28563.10 than its Muslim counterpart (the reference category).

The result of our study supports the argument put by [40] that wealthy individuals often consume highly conspicuously, since it shows that total household income has a positive and statistically significant effect on the level of conspicuous consumption in the wedding ceremony, at 1 per cent level of significance. It indicates that ceteris paribus, as household yearly income increases by Nakfa 1000, it's average conspicuous consumption on wedding ceremony increases by Nakfa 394. Thus, households with a higher level of income, spend relatively more conspicuously on wedding celebrations compared to lower income households.

Finally, financial support from abroad for the lane of marriage has a positive and statistically significant effect on the level of conspicuous consumption on the wedding ceremony, even at low significance levels. This indicates that ceteris paribus, a household which receives financial support from abroad has, on the average, a higher level of conspicuous consumption on wedding ceremony by Nakfa 50.6 thousand, as compared to those who do not receive any financial support.

The bottom part of Table 2 provides summary statistics of the regression. The F-Statistic of 14.6697, which measures the overall significance of the model, shows that, jointly, all the explanatory variables have a significant effect on the dependent variable, or the model is statistically significant even at low significance levels (e.g. 0.1 per cent). Moreover, the coefficient of determination $\left(\mathrm{R}^{2}\right)$ indicates that 72.28 per cent of the total variation in household conspicuous consumption on a wedding ceremony is explained by the independent variables, while the remaining 27.72 per cent is explained by the error term (Ui). Diagnostic tests such as serial correlation, functional form, normality and heteroscedasticity are performed to ensure the appropriateness of the 
fitted model. The model has passed the Breusch-Godfrey Serial Correlation LM Test, Breusch-Pagan-Godfrey as well as a White test for heteroscedasticity and histogram- normality tests implying that the fitted model is appropriate.

\section{Conclusion and recommendations}

Conspicuous consumption, which is a universal practice, is generally seen by researchers as a processor means to signal or maintain status and other social benefits, mainly through the consumption of luxury goods and services with less productive purposes. One of the conspicuous consumption spending, households engaged in, is extravagant spending on wedding ceremonies. Our study focuses on the determinants of conspicuous consumption spending on wedding ceremony in Adi-Keih town, Eritrea. The study used data from a sample of 102 households, who had wedding ceremonies between May 2017 and May 2018. In our research, we found that the average expenditure on wedding ceremony per household is about Nakfa 81,898, which is much higher than the average yearly income of Nakfa 39,549. Moreover, the result of the study shows that age, religion, and education level of head of household, the yearly income of the household and financial assistance from abroad are the factors which have the more significant effects on the level of conspicuous consumption on wedding ceremony. Based on the findings of the study, the following recommendations can be made:

- Intensive awareness campaign through seminars, mass media, radio, TV, magazines...etc. towards the negative impact of conspicuous spending on wedding ceremonies on investment, capital formation and the overall economy, specifically towards younger household head should be given.

- Provide rewards for exemplary households who avoid conspicuous wedding ceremony expenditures and announce them in public media to promote awareness of the society.

- A unique awareness campaign should be directed towards Eritrean diaspora because as to the findings of our study, financial assistance from abroad is one of the main factors for lavish spending on wedding ceremonies.

- Religious institutions, especially the Christian churches, should play their role in the improvement of awareness of its followers since Christians spend more on wedding ceremonies compared to their Muslim counterparts.

- Households with higher income should be advised to spend their money on valuable investments that can help the brides' future livelihood and the economy.

\section{References:}

[1]. Amaldoss, W., \& Jain, S. (2005). Pricing of conspicuous goods: A competitive analysis of social effects. Journal of Marketing Research, 42(1), 30-42.

[2]. Amaldoss, W., \& Jain, S. (2005). Conspicuous consumption and sophisticated thinking. Management Science, 51(10), 1449-1466.

[3]. Anderson, S. (2003). Why dowry payments declined with modernization in Europe but are rising In India. Journal of Political Economy, 111(2), 269-310.

[4]. Arnould, E.J. (1989). Toward a broadened theory of preference formation and the diffusion of innovations: cases from Zinder Province, Niger Republic. Journal of Consumer Research, 16(2), 239-267.

[5]. Bagwell, L. S., \&Bernheim, B. D. (1996). Veblen effects in a theory of Conspicuous Consumption. The American Economic Review, 86(3), 349-473.

[6]. Banerjee, A. V., \&Duflo, E. (2007). The economic lives of the poor. Journal of Economic Perspective, 21(1), 141168.

[7]. Basmann, R. L., Molina, D. J., \&Slottje, D. J. (1988). A note on measuring Veblen's theory of conspicuous consumption. The Review of Economics and Statistics, 70(3), 531-535.

[8]. Basu, K. (1989). A theory of association: Social status, price and markets. Oxford Economic Papers, 41(4), 635671.

[9]. Belk, R. W. (1988). Third World consumer culture", in Kumku, E., \&Firat A. F. (Eds.), Marketing and development: Towards broader dimensions (pp. 103-127). Greenwich: JAI Press.

[10].Bloch, F., Rao, V., \& Desai, S. (2001). Poverty and public celebrations in rural India. Annals of the American Academy of Political and Social Sciences, 563(1), 85-103.

[11].Bloch, F., Rao, V., \& Desai, S. (2004). Wedding celebrations as conspicuous consumption: Signaling social status in rural India. The Journal of Human Resources, 39, 675-695.

[12].Bonsu, S. K., \& Belk, R. W. (2003). Do not go cheaply into that good night: Death-ritual consumption in Asante, Ghana. Journal of Consumer Research, 30(1), 41-55. 
[13].Campbell, C. (1995). Conspicuous confusion? A critique of Veblen's theory of conspicuous consumption. Sociological Theory, 13(1), 37-47.

[14].Case, A., Garrib, A., Menendez, A., \&Olgiati, A. (2013). Paying the piper: The high cost of funerals in South Africa. Economic Development and Cultural Change, 62(1), 1-20.

[15].Chao, A., \& Schor, J. B. (1998). Empirical tests of status consumption: Evidence from Women's Cosmetics. Journal of Economic Psychology, 19(1), 107-131.

[16].Charles, K. K., Hurst, E., \&Roussanov N. (2009). Conspicuous consumption and race. The Quarterly Journal of Economics, 124(2), 425-467.

[17].Childers, T. L., \& Rao, A. R. (1992). The influence of familial and peer-based reference groups on consumer decisions. Journal of Consumer research, 19(2), 198-211.

[18].Corneo, G., \& Oliver, J. (1997). Conspicuous consumption, snobbism and conformism. Journal of Public Economics, 66, 55-71.

[19].Duesenberry, J. S. (1949). Income, Saving and the theory of consumer behaviour. Harvard: Cambridge.

[20].Frank, R. (1985).The Demand for unobservables and other nonpositional goods. American Economic Review, 75(1), 101-116.

[21].Frank, R.H. (1986). Choosing the right pond. Oxford: Oxford University Press.

[22].Friehe, T., \&Mechtel, M. (2012). Conspicuous consumption and communism: Evidence from East and West Germany. CESifo Working Paper Series No. 3922. Retrieved from http://ssrn.com/abstract=2144175.

[23].Fullbrook, E. (2002). Intersubjectivity in economics: agents and structures. London: Routledge.

[24].Glazer, A., \& Kai, A. K. (1996). A signalling explanation for charity. American Economic Review, 86(4), 10191028.

[25].Grant, I. (2004). Communicating with young people through the eyes of marketing practitioners. Journal of Marketing Management, 20(5-6), 591-606.

[26].Grubb, E. L., \& Grathwohl, H. L. (1967). Consumer self-concept, symbolism and market behaviour: A theoretical approach. Journal of Marketing, 31(4) Part 1, 22-27.

[27].Heffetz, O. (2011). A test of conspicuous consumption: Visibility and income elasticities. Review of Economics and Statistics, 93(4), 1101-1117.

[28]. Ireland, N.J. (1994). On limiting the market for status signals. Journal of Public Economics, 53(1), 91-110.

[29].Jaikamur, S., \& Sarin, A. (2015). Conspicuous consumption and income inequality in an emerging economy: Evidence from India. Marketing Letters, 26(3), 279-292.

[30].Kaus, W. (2013). Conspicuous consumption and race: Evidence from South Africa. Journal of Development Economics, 100(1), 63-73.

[31].Linssen, R., Van Kempen, L. \&Kraaykamp, G. (2011). Subjective well-being in rural India: The curse of conspicuous consumption. Social Indicators Research, 101(1), 57-72.

[32].Mason, R. (1981). Conspicuous Consumption: A Study of Exceptional Consumer Behaviour. New York: St. Martin's Press.

[33].Memushi, A. (2014). Conspicuous consumption and Albanians: Determinant factors. South-Eastern Europe Journal of Economics 12(1), 65-87.

[34].Moav, O., \&Neeman, Z. (2008). Conspicuous consumption, human capital, and poverty. Discussion Paper No. 6864, Centre for Economic Policy Research, London EC1V 7RR, UK.

[35].Mullins, P.R. (1999). Race and Affluence: An Archaeology of African American and Consumer Culture. New York: Kluwer Academic/Plenum Publishers.

[36].O'cass, A., \& McEwen, H. (2004). Exploring consumer status and conspicuous consumption. Journal of consumer behaviour, 4(1), 25-39.

[37]. Ordabayeva, N., \&Chandon, P. (2011). Getting ahead of the Joneses: When equality increases conspicuous consumption among bottom-tier consumers. Journal of Consumer Research, 38(1), 27-41.

[38].Özpinar, Ş., Aldemir, N. C. \&Özpinar, Ö. (2010). Consumption perception in Turkey within the context of globalization, in Rethinking Global Society: The Bauman Institute International Launch Conference. Retrieved from http://baumaninstitute.leeds.ac.uk/ conference/conference-papers/ozpinar-aldemir-ozpinar/.

[39].Page, C. (1992). A History of Conspicuous Consumption.InRudmin, F., \&Richins, M. (Eds.), Meaning, measure, and morality of materialism (pp. 82-87). Provo: Association for Consumer Research.

[40].Patsiaouras, G., \& Fitchett, J. A. (2012). The evolution of conspicuous consumption. Journal of Historical Research in Marketing, 4 (1), 154-176.

[41].Pauli, J \&Dawids, F. (2017). The struggle for marriage: Elite and non-elite weddings in rural Namibia. Anthropology Southern Africa, 40(1), 15-28.

[42].Rae, J. (1834). The sociological theory of capital. New York: Macmillan.

[43].Rao, V. (2001). Poverty and public celebrations in Rural India. The World Bank.

[44].Scheetz, T. (2004). A Modern Investigation of Status Consumption. Retrieved from URL: http:// www.case.edu/artsci/dean/elf/presentationsreports.html.

[45].Sims-Muhammad, T. Y. (2012). Young adult perception and attitude toward conspicuous consumption and poverty. Journal of Social Sciences, 8(4), 512-518.

[46].Spero, I., \& Stone, M. (2004). Agents of change: How young consumers are changing the world of marketing. Qualitative Market Research: An International Journal, 7(2), 153-159.

[47].Trigg, A. B. (2001). Veblen, Bourdieu and conspicuous consumption. Journal of Economic Issues, 35(1), 99-115. 
[48].Van Kempen, L. (2004). Are the poor willing to pay a premium on designer Labels? A field experiment in Bolivia. Oxford Development Studies, 32(2), 205-224.

[49].Veblen, T. (1899). The Theory of the Leisure Class: An Economic Study of Institutions. New York: Random House.

[50].Wijnen, V. (2017). Conspicuous consumption: An empirical analysis of Sub-Sahara Africa (Masters thesis, Radboud University).

[51].World Bank. (2014). Living standards measurement study in Central, Ethiopia. Rural Socioeconomic Survey 2011-2012.

[52].Yoon, J., \& Seok, H. (1996). Conspicuous consumption and social status in Korea: An assessment of reciprocal effects. Korea Journal of Population and Development, 25(2), 333-354. 